\title{
Polymorphic variants of SLCO1B1 in neonatal hyperbilirubinemia in China
}

\author{
Jiebo Liu*, Jun Long, Shaofang Zhang, Xiaoyan Fang and Yuyuan Luo
}

\begin{abstract}
Background: To evaluate the association between the genetic polymorphism of the solute carrier organic anion transporter family member 1B1 (SLCO1B1, also known as organic anion transport polypeptide C) and hyperbilirubinemia in Chinese neonates.

Methods: 183 infants with hyperbilirubinemia and 192 control subjects from the Fifth People's Hospital of Shenzhen were recruited. Polymerase chain reaction, restriction fragment length polymorphisms and agarose gel electrophoresis techniques were used to detect genetic variants of SLCO1B1.

Results: The study revealed that SLCO1B1 $388 \mathrm{G}>$ A occurred significantly more frequently in neonates with hyperbilirubinemia than in controls $(\mathrm{RR}=1.50 ; 95 \% \mathrm{Cl}: 1.13-2.00)$. There were no significant differences in SLCO1B1 $521 \mathrm{~T}>\mathrm{C}$ between the hyperbilirubinemia and the control group (RR, 1.00; 95\% Cl, 0.72-1.40). No carriage of the C to A substitution at nucleotide 463 was detected.
\end{abstract}

Conclusion: The SLCO1B1 388 G > A variant is associated with neonatal hyperbilirubinemia in Chinese neonates.

Keywords: Polymorphisms, Neonatal hyperbilirubinemia, Case-control study, Organic anion transport polypeptide C

\section{Background}

Neonatal hyperbilirubinemia is one of the most common problems encountered in newborns, occurring in up to $60 \%$ of healthy full-term and $80 \%$ of preterm newborns during the first week of life [1]. Most cases are physiological and do not result in serious consequences, but systematic failure to identify at-risk infants has been associated with an increased risk of severe hyperbilirubinemia, which is one of the reasons for the higher incidence of kernicterus, and may result in neurodevelopmental abnormalities such as hearing loss, athetosis, and rarely, intellectual deficits [2].

Bilirubin, the hydrophobic end product of heme degradation, is metabolized in the hepatocyte to hydrophilic conjugates, which are then efficiently eliminated in the bile [3]. Following uptake from the plasma, unconjugated bilirubin is transported from the blood circulation to the liver by organic anion transporter polypeptide 2 (OATP2), also known as OATP-C and LST1, which is an uptake transporter located on the

\footnotetext{
*Correspondence: jiebol@126.com

Department of Pediatrics, The Fifth People's Hospital of Shenzhen, No. 47 Friendship Road, Luohu District, 518001 Shenzhen, China
}

basolateral (sinusoidal) membrane of human hepatocytes, encoded by the gene of the solute carrier organic anion transporter family member 1B1 (SLCO1B1) [4]. At this point, OATP1B1 is conjugated with glucuronic acid and bilirubin in the endoplasmic reticulum through a catalytic reaction involving UDP-glucuronosyltransferase 1A1 (UGT1A1), which results in conjugated bilirubin, also known as water-soluble bilirubin. The conjugated bilirubin glucuronides are excreted in the bile, pass through the intestine, and are deconjugated by bacteria that reduce some of the bilirubin to urobilinogens. Approximately $80 \%$ of the urobilinogens are excreted in the stool and the remainder is either reabsorbed into the enterohepatic circulation or goes to the kidneys to be excreted in urine [3]. Thus, OATP1B1 or UGT1A1 are responsible for bilirubin conjugation, and it follows that a defect in the function of either may result in unconjugated hyperbilirubinemia [5].

In our previous study, we found that the UGT1A1 $211 \mathrm{G}>\mathrm{A}$ mutation is associated with neonatal hyperbilirubinemia in Asians [6]. Recently, studies have suggested that variations of $388 \mathrm{G}>\mathrm{A}, 521 \mathrm{~T}>\mathrm{C}, 463$ $\mathrm{C}>\mathrm{A}$ of the SLCO1B1 gene may predispose subjects to 
neonatal hyperbilirubinemia by limiting hepatic bilirubin uptake [7]. A high prevalence of $388 \mathrm{G}>\mathrm{A}(73.4 \%)$ and $521 \mathrm{~T}>\mathrm{C}(14.0 \%)$ variants occurring in Chinese subjects [8]. A $16 \%$ prevalence of $463 \mathrm{C}>\mathrm{A}$ variants has been reported in Europeans and Americans, but this variant appear to be of low prevalence in the Chinese population [9]. Moreover, neonatal hyperbilirubinemia is known to occur more frequently and to be more severe in Asians than in Caucasians [10]. We hypothesized that the SLCO1B1 mutation may be one of the risk factors for neonatal hyperbilirubinemia, which possibly accounts for the variability in prevalence rates in the Chinese neonates. Therefore, we conducted a case-control study of three variants $(388 \mathrm{G}>\mathrm{A}, 521 \mathrm{~T}>\mathrm{C}, 463 \mathrm{C}>\mathrm{A})$ of SLCO1B1 and investigated their association with neonatal hyperbilirubinemia in the Chinese neonates.

\section{Methods}

\section{Patients and controls}

The subjects were term newborn infants, with a gestational age of more than 37 weeks, who were born between August 2011 and January 2012 at the Fifth People's Hospital of Shenzhen, China. We excluded newborn infants who were birth asphyxia, polycythemia, hypothermia, hypoglycemia, cephalohematoma, hypothyroidism, glucose-6-phosphate dehydrogenase (G-6$\mathrm{PD})$ deficiency, or hemolytic disease of $\mathrm{ABO}$ and $\mathrm{Rh}$ incompatibilities. We also excluded newborn infants whose mothers were maternal diabetes, hypertension in pregnancy, intrauterine infection.

Neonatal hyperbilirubinemia was defined as neonates with total serum bilirubin levels exceeding the 95th percentile, according to the Bhutani nomogram [11]. Total serum bilirubin levels were monitored and the causes of neonatal hyperbilirubinemia were investigated and treated following the 2004 American Academy of Pediatrics (AAP) guidelines. The control group consisted of neonates with total serum bilirubin levels below the 40th percentile as defined by the Bhutani nomogram [11]. The case-control study included a total of 183 infants with hyperbilirubinemia and 192 control subjects.

\section{Molecular analysis}

The polymerase chain reaction-restriction fragment length polymorphism (PCR-RFLP) method was applied to detect three known variant sites (nucleotides 388, 463 and 521) of the SLCO1B1 gene. The natural or mutagenic primers, restriction enzymes, and digested restriction fragment sizes of the five known variants are listed in Table 1. The PCR mixture $(20 \mu \mathrm{L})$ consisted of $200 \mathrm{ng}$ of DNA, $20 \mathrm{ng}$ of each primer, $1.25 \mathrm{mM}$ of each dNTP $(3.2 \mu \mathrm{L})$, buffer solution $(100 \mathrm{mM}$ Tris $\mathrm{HCl}, 500 \mathrm{mM} \mathrm{KCl}$, $15 \mathrm{mM} \mathrm{MgCl}_{2}$, and $0.01 \%$ gelatin), and $0.4 \mathrm{U}$ of Taq DNA polymerase. The PCR amplification was carried out in a thermal cycler for 35 cycles of denaturation for $1 \mathrm{~min}$ at $94^{\circ} \mathrm{C}$, annealing for $1 \mathrm{~min}$ at $55^{\circ} \mathrm{C}$, primer extension for $1 \mathrm{~min}$ at $72^{\circ} \mathrm{C}$, and a final extension for $10 \mathrm{~min}$ at $72^{\circ} \mathrm{C}$. The PCR product was digested with the appropriate restriction enzyme and analyzed on a 3\% agarose gel.

\section{Statistical analysis}

We analyzed the collected data using Stata software (version 9.0; Stata Corp. LP, College Station, TX, USA). Genotype results were analyzed as the hyperbilirubinemic group versus the control group. Allele frequencies of genes were determined by calculating the percentage of variant genes within the total number in the study population. Comparisons between the study group and the control group were performed with chi-square test and Fisher's exact test when expected values were $<5 \%$. Results are given as relative risk (RR) with $95 \%$ confidence intervals $(\mathrm{CI})$.

\section{Ethical considerations}

The Ethics Committee on Human Experimentation of the Faculty of Medicine, Fifth People's Hospital of Shenzhen, China, approved the study protocol. Informed consent was obtained from the parents of each study infant.

\section{Results}

A total of 375 neonates were enrolled into the study. Newborns with G6PD deficiency were not found in the study group. The demographic and clinical data of the hyperbilirubinemic group and the control group is summarized in Table 2 . There were no statistically significant

Table 1 Natural or mutagenesis primers, restriction enzymes, and SLCO1B1 genes and variations

\begin{tabular}{|c|c|c|c|c|}
\hline Positions (cDNA) & Primers & Sequences & Restriction enzymes & Results (bp) \\
\hline 388 & $388 \mathrm{~F}$ & 5'ATAATGGTGCAAATAAAGGGG3' & Taq I & $\mathrm{G} 128+63+23$ \\
\hline $\mathrm{G} \rightarrow \mathrm{A}$ & $388 \mathrm{R}$ & 5'ACTATCTCAGGTGATGCTCTA3' & & A $151+63$ \\
\hline 521 & $521 \mathrm{~F}$ & 5'TTGTCAAAGTTTGCAAAGTG3' & Hha I & T 209 \\
\hline $\mathrm{T} \rightarrow \mathrm{C}$ & $521 R$ & 5'GAAGCATATTACCCATGAGC3' & & C $189+20$ \\
\hline 463 & $463 \mathrm{~F}$ & 5'ATAATGGTGCAAATAAAGGGG3' & Hpa II & $C 205+19$ \\
\hline$C \rightarrow A$ & $463 R$ & 5'ACCTITTCCCACTATCTCCG3' & & A 224 \\
\hline
\end{tabular}


Table 2 Demographic and clinical data of newborn infants enrolled into the study

\begin{tabular}{|c|c|c|c|}
\hline Data & $\begin{array}{l}\text { Hyperbilirubinemia } \\
\text { group }(n=183)\end{array}$ & $\begin{array}{c}\text { Control group } \\
(n=192)\end{array}$ & $\mathrm{p}$-value \\
\hline $\begin{array}{l}\text { Gestational age } \\
\text { (week) }\end{array}$ & $38.35 \pm 1.76$ & $38.12 \pm 1.53$ & 0.18 \\
\hline Birth weight (g) & $3238.32 \pm 409.37$ & $3194.53 \pm 399.61$ & 0.29 \\
\hline Sex: male & 98 (53.55\%) & 102 (53.12\%) & 0.98 \\
\hline \multicolumn{4}{|l|}{ Delivery: } \\
\hline Normal & 118 (64.48\%) & 121 (63.02) & 0.85 \\
\hline Cesarean section & 45 (24.59\%) & 49 (25.52\%) & 0.93 \\
\hline $\begin{array}{l}\text { Forceps and vacuum } \\
\text { extraction }\end{array}$ & $20(10.93 \%)$ & 22 (11.46\%) & 0.99 \\
\hline \multicolumn{4}{|l|}{ Feeding: } \\
\hline Breast milk only & 46 (25.14\%) & 54 (28.13\%) & 0.59 \\
\hline $\begin{array}{l}\text { Formula mixed } \\
\text { with breast milk }\end{array}$ & 94 (51.37\%) & $97(50.52 \%)$ & 0.95 \\
\hline Formula only & $43(23.49 \%)$ & 41 (21.35\%) & 0.71 \\
\hline $\begin{array}{l}\text { Excessive weight loss } \\
\text { ( }>3 \% \text { per day or } \geq 10 \% \\
\text { of birth weight) }\end{array}$ & $112(61.2 \%)$ & 119 (61.98\%) & 0.96 \\
\hline
\end{tabular}

differences in gestational age, birth weight, sex, delivery, feeding between the two groups.

Analysis of SLCO1B1 at nt 388 revealed that 76 of the 183 (41.53\%) neonates in the hyperbilirubinemic group demonstrated the transition mutation (17 homozygous and 59 heterozygous) compared to 53 of 192 (27.60\%) in the control group (10 homozygous and 43 heterozygous). There were significant differences between genotype distributions of the SLCO1B1 $388 \mathrm{G}>$ A mutation (Table 3). The risk of neonatal hyperbilirubinemia was higher in SLCO1B1 $388 \mathrm{G}>$ A allele carriers (A/A + G/A) than in GG allele carriers (RR, 1.50; 95\% CI, 1.13-2.00).

The allele frequency of the variant SLCO1B1 at nt 388 in infants in the hyperbilirubinemic group was 0.254 , which was significantly higher than that observed in the control group (0.164, $\mathrm{p}=0.003$; Table 3). The likelihood of developing neonatal hyperbilirubinemia was 1.55 times higher in infants with the A allele in SLCO1B1 $388 \mathrm{G}>\mathrm{A}$ than in infants with the $\mathrm{G}$ allele $(95 \% \mathrm{CI}$, $1.16-2.06)$.
Analysis of the variant of SLCO1B1 gene at nt 521 revealed an allele frequency of 46 of $183(25.14 \%)$ in neonates in the hyperbilirubinemic group (11 homozygous and 35 heterozygous), compared to 51 of 192 (26.56\%) in the control group (9 homozygous and 42 heterozygous). There were no statistically significant differences in the risk of neonatal hyperbilirubinemia between SLCO1B1 $521 \mathrm{~T}>\mathrm{C}$ allele carriers $(\mathrm{C} / \mathrm{C}+\mathrm{C} / \mathrm{T})$ and T/T allele carriers (RR, 0.95; 95\% CI, 0.67-1.34).

The allele frequency of the variant SLCO1B1 at nt 521 in infants in the hyperbilirubinemic group was 0.156 , compared with 0.155 in the control group (Table 3). There were no statistically significant differences in the risk of neonatal hyperbilirubinemia between those with the T allele in SLCO1B1 $521 \mathrm{~T}>\mathrm{C}$ and those with the $\mathrm{C}$ allele (RR, 1.00; 95\% CI, 0.72-1.40). No carriage of the C to A substitution at nucleotide 463 was detected (Table 3).

\section{Discussion}

Various factors are involved in the development of neonatal hyperbilirubinemia, including the SLCO1B1 gene, which requires further investigation as SLCO1B1 encodes a liver-specific member of the organic anion transporter family. The encoded protein is a transmembrane receptor that can rapidly and selectively uptake bilirubin into hepatocytes [12]. Variations within the coding region of the SLCO1B1 gene may result in dysfunction of SLCO1B1 due to abnormal structure [13]. In adult liver disease, polymorphism in the gene encoding this protein is a major determinant of serum bilirubin levels [14]. These findings indicate that variations in the SLCO1B1 gene are possibly associated with neonatal hyperbilirubinemia. The most frequent mutations of SLCO1B1 in the Chinese population are the $388 \mathrm{G}>\mathrm{A}$ mutation and the $521 \mathrm{~T}>\mathrm{C}$ mutation [15]. The prevalence of $463 \mathrm{C}>\mathrm{A}$ variants of SLCO1B1 gene is low in Chinese, but high in Europeans and Americans [16]. Neonatal hyperbilirubinemia is more frequent and more severe in Chinese than in Europeans and Americans [17], and the SLCO1B1 mutation may explain the variability in the prevalence of neonatal hyperbilirubinemia among different ethnic groups.

Our study revealed that the $388 \mathrm{G}>\mathrm{A}$ mutation of the SLCO1B1 gene is associated with neonatal

Table 3 Distributions of SLCO1B1 genotypes and allele frequencies with variants at nucleotide 388, 521 and 463

\begin{tabular}{|c|c|c|c|c|c|c|}
\hline Variants of genes & Group & Homozygous wild type & Heterozygous & Homozygous mutant type & Allele frequency & $\mathrm{p}$-value \\
\hline SLCO1B1 & Case & 107 & 59 & 17 & 0.254 & \\
\hline nt 388 & Control & 139 & 43 & 10 & 0.164 & 0.003 \\
\hline SLCO1B1 & Case & 137 & 35 & 11 & 0.156 & \\
\hline nt 521 & Control & 141 & 42 & 9 & 0.155 & 0.937 \\
\hline SLCO1B1 & Case & 183 & 0 & 0 & 0 & \\
\hline nt 463 & Control & 192 & 0 & 0 & 0 & - \\
\hline
\end{tabular}


hyperbilirubinemia in Chinese neonates. Assessment of the frequency of the $\mathrm{G}$ allele in the $388 \mathrm{G}>\mathrm{A}$ mutation in hyperbilirubinemic and in control infants $(0.254$ and 0.164 , respectively) revealed significant differences. The likelihood of developing neonatal hyperbilirubinemia was 1.55 times higher in $388 \mathrm{G}>\mathrm{A}$ mutants with the A allele than in those with the $G$ allele. The allele frequency of the variant SLCO1B1 at nt 521 in infants in the hyperbilirubinemic group did not demonstrate a statistically significant difference compared with the control group (0.156 and 0.155 , respectively). No carriage of the $\mathrm{C}$ to A substitution at nucleotide 463 of the SLCO1B1 gene was detected. The results of our case-control study were consistent with those of a previous study involving the Chinese neonates, which is conflicting with the study from Brazil [18]. The allele frequency of SLCO1B1 (388A > G) in chinese populations was 63.5\% [19], which was higher than Brazilians (white was $50.4 \%$ and black was 35.1\%) [20]. The genetics of racial differences might explain the different association between the genetic polymorphism of SLCO1B1 and neonatal hyperbilirubinemia among different ethnic groups.

In genetic epidemiology, a genome-wide association study (GWAS) examines all or most of the genes of different variations associated with different diseases. It is more powerful than a case-control study for single genetic polymorphisms. Recently, one GWAS based on European adult populations suggested that genetic variations of SLCO1B1 influence bilirubin levels [21]. Another cohort from the Mayo Genome Consortia also showed that genetic variants of SLCO1B1 were associated with total bilirubin levels in Americans [22]. However, both a GWAS based on European adult populations [23] and a large-scale GWAS based on Korean adults [24] contradicted these results, suggesting that genetic variations of SLCO1B3 influence bilirubin levels, not SLCO1B1. The SLCO1B3 gene is also a member of the OATP family, which is highly expressed in the basolateral membrane of hepatocytes. SLCO1B3 and SLCO1B1 share $80 \%$ amino acid sequence identity and have similar substrate selectivity [25]. Functionality between these two human transporters in the OATP family can be distinguished using estrone-3-sulfate, a SLCO1B1-selective ligand, and cholecystokinin octapeptide, a SLCO1B3-selective ligand [26]. Whether SLCO $1 \mathrm{~B} 3$ and SLCO1B1 are associated with bilirubin levels or differentially contribute in a population-specific fashion, needs further investigation.

\section{Conclusions}

The cohort study which analyzed the genetic association was time-consuming, laborious, and high costly, so, there was still not one prospective cohort study which assessed genetic variations associated with hyperbiliru- binemia. Our case-control study found that the variant SLCO1B1 $388 \mathrm{G}>\mathrm{A}$ is associated with neonatal hyperbilirubinemia in Chinese neonates; further prospective cohort study is need to conform the association.

\section{Competing interests}

The authors declare that they have no competing interests.

\section{Authors' contributions}

$J$, SZ carried out the molecular genetic studies; JL, XF participated in the sequence alignment; JL, YL design of experiment and drafted the manuscript; SZ, XF collected and interpreted the data; JL, SZ wrote the manuscript; JL, SZ, XF, YL reviewed the Manuscript. All authors read and approved the final manuscript.

\section{Acknowledgements}

We thank the physicians, the patients and their families who participated in this work for their kind help.

Received: 13 May 2013 Accepted: 10 August 2013

Published: 12 August 2013

\section{References}

1. Sarici SU: Incidence and etiology of neonatal hyperbilirubinemia. J Trop Pediatr 2010, 56:128-129.

2. Maisels MJ: Risk assessment and follow-up are the keys to preventing severe hyperbilirubinemia. J Pediatr (Rio J) 2011, 87:275-276.

3. Vitek L, Ostrow JD: Bilirubin chemistry and metabolism; harmful and protective aspects. Curr Pharm Des 2009, 15:2869-2883.

4. Wolkoff AW, Samuelson AC, Johansen KL, Nakata R, Withers DM, Sosiak A: Influence of $\mathrm{Cl}$ - on organic anion transport in short-term cultured rat hepatocytes and isolated perfused rat liver. J Clin Invest 1987, 79:1259-1268.

5. Lin R, Wang X, Wang Y, Zhang F, Wang Y, Fu W, Yu T, Li S, Xiong M, Huang $W$, Jin L: Association of polymorphisms in four bilirubin metabolism genes with serum bilirubin in three Asian populations. Hum Mutat 2009, 30:609-615.

6. Long J, Zhang S, Fang X, Luo Y, Liu J: Neonatal hyperbilirubinemia and Gly71Arg mutation of UGT1A1 gene: a Chinese case-control study followed by systematic review of existing evidence. Acta Paediatr 2011, 100:966-971.

7. Watchko JF, Lin Z: Exploring the genetic architecture of neonatal hyperbilirubinemia. Semin Fetal Neonatal Med 2010, 15:169-175.

8. Xu LY, He YJ, Zhang W, Deng S, Li Q, Zhang WX, Liu ZQ, Wang D, Huang YF, Zhou HH, Sun ZQ: Organic anion transporting polypeptide-1B1 haplotypes in Chinese patients. Acta Pharmacol Sin 2007, 28:1693-1697.

9. Tirona RG, Leake BF, Merino G, Kim RB: Polymorphisms in OATP-C: identification of multiple allelic variants associated with altered transport activity among European- and African-Americans. J Biol Chem 2001, 276:35669-35675.

10. Setia S, Villaveces A, Dhillon P, Mueller BA: Neonatal jaundice in Asian, white, and mixed-race infants. Arch Pediatr Adolesc Med 2002, 156:276-279.

11. American Academy of Pediatrics: Management of hyperbilirubinemia in the newborn infant 35 or more weeks of gestation. Pediatrics 2004, 114:297-316.

12. DerDeure WMV, Friesema EC, DeJong FJ, DeRijke YB, DeJong FH, Uitterlinden AG, Breteler MM, Peeters RP, Visser TJ: Organic anion transporter 1B1: an important factor in hepatic thyroid hormone and estrogen transport and metabolism. Endocrinology 2008, 149:4695-4701.

13. Pasanen MK, Neuvonen PJ, Niemi M: Global analysis of genetic variation in SLCO1B1. Pharmacogenomics 2008, 9:19-33.

14. Huang CS, Huang MJ, Lin MS, Yang SS, Teng HC, Tang KS: Genetic factors related to unconjugated hyperbilirubinemia amongst adults. Pharmacogenet Genomics 2005, 15:43-50.

15. Jada SR, Xiaochen S, Yan LY, Xiaoqiang X, Lal S, Zhou SF, Ooi LL, Chowbay B: Pharmacogenetics of SLCO1B1: haplotypes, htSNPs and hepatic expression in three distinct Asian populations. Eur J Clin Pharmacol 2007, 63:555-563

16. Pasanen MK, Backman JT, Neuvonen PJ, Niemi M: Frequencies of single nucleotide polymorphisms and haplotypes of organic anion transporting 
polypeptide 1B1 SLCO1B1 gene in a Finnish population. Eur J Clin Pharmacol 2006, 62:409-415.

17. Beal AC, Chou SC, Palmer RH, Testa MA, Newman C, Ezhuthachan S: The changing face of race: risk factors for neonatal hyperbilirubinemia. Pediatrics 2006, 117:1618-1625.

18. Alencastro De Azevedo L, Reverbel Dasilveira T, Carvalho CG, Martins DeCastro S, Giugliani R, Matte U: UGT1A1, SLCO1B1, and SLCO1B3 polymorphisms vs. neonatal hyperbilirubinemia: is there an association? Pediatr Res 2012, 72:169-173.

19. Ho WF, Koo SH, Yee JY, Lee EJ: Genetic variations of the SLCO1B1 gene in the Chinese, Malay and Indian populations of Singapore. Drug Metab Pharmacokinet 2008, 23:476-482.

20. Sortica Vde A, Ojopi EB, Genro JP, Callegari-Jacques S, Ribeiro-Dos-Santos A, De Moraes MO, Romano-Silva MA, Pena SD, Suarez-Kurtz G, Hutz MH: Influence of genomic ancestry on the distribution of SLCO1B1, SLCO1B3 and $A B C B 1$ gene polymorphisms among Brazilians. Basic Clin Pharmacol Toxicol 2012, 110:460-468.

21. Johnson AD, Kavousi M, Smith AV, Chen MH, Dehghan A, Aspelund T, Lin JP, Van Duijn CM, Harris TB, Cupples LA, Uitterlinden AG, Launer L, Hofman A, Rivadeneira F, Stricker B, Yang Q, O'Donnell CJ, Gudnason V, Witteman JC: Genome-wide association meta-analysis for total serum bilirubin levels. Hum Mol Genet 2009, 18:2700-2710

22. Bielinski SJ, Chai HS, Pathak J, Talwalkar JA, Limburg PJ, Gullerud RE, Sicotte H, Klee EW, Ross JL, Kocher JP, Kullo IJ, Heit JA, Petersen GM, De Andrade M, Chute CG: Mayo Genome Consortia: a genotype-phenotype resource for genome-wide association studies with an application to the analysis of circulating bilirubin levels. Mayo Clin Proc 2011, 86:606-614.

23. Sanna S, Busonero F, Maschio A, McArdle PF, Usala G, Dei M, Lai S, Mulas A, Piras MG, Perseu L, Masala M, Marongiu M, Crisponi L, Naitza S, Galanello R, Abecasis GR, Shuldiner AR, Schlessinger D, Cao A, Uda M: Common variants in the SLCO1B3 locus are associated with bilirubin levels and unconjugated hyperbilirubinemia. Hum Mol Genet 2009, 18:2711-2718.

24. Kang TW, Kim HJ, Ju H, Kim JH, Jeon YJ, Lee HC, Kim KK, Kim JW, Lee S, Kim $J$, Kim SY, Kim YS: Genome-wide association of serum bilirubin levels in Korean population. Hum Mol Genet 2010, 19:3672-3678.

25. Konig J: Uptake transporters of the human OATP family: molecular characteristics, substrates, their role in drug-drug interactions, and functional consequences of polymorphisms. Handb Exp Pharmacol 2011, 201:1-28.

26. Seithel A, Glaeser $H$, Fromm MF, König J: The functional consequences of genetic variations in transporter genes encoding human organic aniontransporting polypeptide family members. Expert Opin Drug Metab Toxicol 2008, 4:51-64.

doi:10.1186/1824-7288-39-49

Cite this article as: Liu et al:: Polymorphic variants of SLCO1B1 in

neonatal hyperbilirubinemia in China. Italian Journal of Pediatrics 2013 39:49.

\section{Submit your next manuscript to BioMed Central and take full advantage of:}

- Convenient online submission

- Thorough peer review

- No space constraints or color figure charges

- Immediate publication on acceptance

- Inclusion in PubMed, CAS, Scopus and Google Scholar

- Research which is freely available for redistribution 